\title{
Gauging flow velocity in 2 positions for discharge calculation in pipes
}

\section{Medindo a velocidade de escoamento em 2 posições para o cálculo da vazão em tubos}

\author{
Victor Emanuel Mello de Guimarães Diniz ${ }^{1}$ Edevar Luvizotto Júnior ${ }^{1}$, Podalyro Amaral de Souza ${ }^{2}$ and Pedro Alves Silva ${ }^{3}$ \\ ${ }^{1}$ Universidade Estadual de Campinas, Campinas, SP, Brasil \\ ${ }^{2}$ Universidade de São Paulo, São Paulo, SP, Brasil \\ ${ }^{3}$ Universidade São Judas Tadeu, São Paulo, SP, Brasil \\ E-mails: vediniz@uol.com.br(VEMGD),edevar@fec.unicamp.br(ELJ),podalyro@usp.br (PAS), lestepas@uol.com.br (PAS)
}

Received: August 15, 2017 - Revised: March 28, 2018 - Accepted: April 09, 2018

\begin{abstract}
This paper utilizes the maximum entropy model to calculate discharges in pipes. The proposed model requires the flow velocities to be gauged in just two positions along the pipe radius to calculate the discharge of any given pipe with circular cross-section regardless its diameter size. A genetic algorithm is used to determine the two parameters of the entropy equation for pipe flow. Three water mains are assessed. The discharge values achieved by the maximum entropy model coupled to the genetic algorithm for two water mains are compared to those achieved by a calibrated AquaProbe ABB electromagnetic flow meter and remain within the device accuracy $( \pm 2 \%)$, as reported by its manufacturer. A Cole type Pitot tube in series with a Venturi tube are used to respectively define three velocity profiles and gauge three different discharges for the third water main. The three discharge values obtained by the maximum entropy model are compared to the ones obtained by the Venturi tube and remain within the presented uncertainties $(3.3 \%, 3.1 \%$ and $2.8 \%$ ) for each discharge gauged by the Venturi tube. The discharge calculation in any given pipe is facilitated by the presented method.
\end{abstract}

Keywords: Discharge calculation; Velocity profile; Genetic algorithm; Maximum entropy; Pipe flow.

\section{RESUMO}

Este artigo usa o modelo de entropia máxima para calcular vazões em tubos. O modelo de entropia máxima requer que as velocidades de escoamento sejam medidas em apenas dois pontos ao longo do raio do tubo para que a vazão seja calculada em qualquer tubo com seção transversal circular, independentemente do tamanho do diâmetro. Um algoritmo genético foi utilizado para determinar os dois parâmetros da equação entropia máxima para escoamento forçado. Três adutoras foram analisadas. Os valores das vazões obtidos pelo modelo de entropia máxima acoplado ao algoritmo genético para duas adutoras foram comparados com os valores obtidos por um medidor de vazão eletromagnético calibrado (AquaProbe ABB) e ficaram dentro da precisão do aparelho ( $\pm 2 \%)$, conforme informado pelo fabricante. Um tubo de Pitot tipo Cole instalado em série com um tubo Venturi foram usados para definir, respectivamente, três diferentes perfis de velocidade e medir três diferentes vazões para a terceira adutora. Os três valores de vazão obtidos pelo modelo de entropia máxima foram comparadas com os valores obtidos pelo tubo Venturi e ficaram dentro das incertezas apresentadas (3,3\%, $3,1 \%$ e 2,8\%) para cada valor de vazão obtido pelo tubo Venturi. O método apresentado facilita o cálculo da descarga em qualquer tubo.

Palavras-chave: Cálculo de vazão; Perfil de velocidade; Algoritmo genético; Entropia máxima; Escoamento em tubo. 


\section{INTRODUCTION}

The discharge calculation in pipes has always been important and nowadays it is becoming more and more important because of the huge amount of water loss due to existing leakages in most hydraulic networks. The water losses cause a big waste of money and sometimes it may cause failure in supplying. Reliable discharge data are useful in the calibration of hydraulic simulation models of hydraulic networks. The discharge is also calculated to estimate the head loss due to friction and to determine if flow is laminar, turbulent or if it is in the critical zone.

The entropy concept is utilized to ground the connection between probabilistic and deterministic worlds, the former being not familiar to hydraulic engineers (CHIU, 1987).

Entropy is a thermodynamic quantity that measures the degree of irreversibility of a system and it is generally associated with what is termed a "disorder" of a thermodynamic system. The entropy concept is already well-established and has been used in statistical mechanics and information theory in which entropy is quantitatively defined in terms of probability (SHANNON, 1948; GOLDMAN, 1953 apud CHIU, 1987). According to the entropy concept, in a steady equilibrium condition a system tends to maximize the entropy under prevailing constraints. From all distribution sets that are governed by these constraints, the principle of Maximum Entropy states that the one with the greatest entropy must be chosen. Thus, through maximization of entropy, it is possible to identify the best probabilities distribution estimation to be assigned to a given system.

Chiu (1988) utilized the maximum entropy model and presented an equation showing the relationship between the entropy parameter and the velocity profile of any given flow in an open channel cross-section. Chiu (1988) revealed the utility of the entropy parameter, as a new hydraulic parameter, and concluded that it shows the significance and importance of the information given by the location and value of the maximum velocity in a cross-section.

Chiu et al. (1993) employed the concepts developed in Chiu $(1987,1988)$ for pipe flow. From the application of the maximum entropy concept, it was possible to model the velocity profile for pipes with circular cross-section. Chiu et al. (1993) rewrote the equation showing the relation between the velocity profile of any given flow for pipes with circular cross-section and the entropy parameter. From the rewritten equation, Chiu et al. (1993) achieved an equation to calculate the mean velocity value in pipe flows with circular cross-section which depends only on the maximum flow velocity and the entropy parameter. It was possible to calculate the discharge in any given pipe flow with circular cross-section utilizing the calculated mean velocity value and multiplying it by the circular cross-section area.

Genetic algorithms are part of evolutionary algorithms and present a population formed of numerous individuals to develop under specific selection rules to a stage that generally maximizes the objective function fitting. Genetic algorithms own some benefits, such as not needing derivative information like a plenty of methods used in optimization, being able to look for optima results regardless the parameters are continuous or discrete etc. The method created by John Holland during the 1960s and 1970s was made popular by one of his postgraduate students, David
Goldberg, who resolved a complicated problem involving gas conveyance control through ducts in his 1983 Ph.D. dissertation (DINIZ; SOUZA; LUVIZOTTOO, 2010).

Kashima, Lee and Nokes (2012) presented the Kinetic Differential Pressure method to measure unsteady discharge in pressurized fluid tubes. The method uses two pressure records to evaluate the temporal discharge at the sampling rate of the pressure sensors. The search explored one of the two possible sources of error, that is, the significance of the linear approximation of the governing equations. The other source of error, that is, the modeling error that represents the inability of the one-dimensional model to reproduce the actual transient behavior, was not explored. The numerical error took into account was the difference between the linearized Kinetic Differential Pressure model and a nonlinear Method of Characteristics. An assessment was carried out in a reservoir-tube-reservoir system with different flow disturbances inserted into the system. The numerical error was just of the order of $1 \%$ for non-resonance frequencies for all trials, but the error was significative if the system was driven at its resonant frequency. The error size shows that the linear approximation of the governing equation has a little effect regardless of the system and signal features if the system is not conducted to its resonant frequency. The outcomes of this search also showed that the presented method is numerically accurate if the system resonance is averted.

A new multi-objective approach without penalties and reliability information for water distribution systems (WDS) design optimization was introduced by Saleh and Tanyimboh (2011). It was based on the union of a robust and fast genetic algorithm known as Non-Dominated Sorting Genetic Algorithm II (NSGA-II) with hydraulic solver EPANET2. Network entropy was used as a measure of reliability of the WDSs. The standard discrete pipe diameters were used as the decision variables in the approach. The complicated issue of the flow directions associated with network entropy calculation was addressed by the proposed approach. The proposal was demonstrated through the design of a well-known hypothetical network in the literature and it was able to reach the Global Maximum Entropy Minimum Cost (GMEMC) for this network. On the other hand, the optimization process took a long time.

Diniz et al. (2013) utilized a maximum entropy model to calculate the discharge of a man-made rectangular channel and two rivers. A genetic algorithm was utilized to set the three parameters of the maximum entropy equation. The discharge calculation values achieved by the maximum entropy model linked with the genetic algorithm were confronted to the discharge calculation values achieved by the velocity-area (utilizing a rotor current meter) method and the acoustic (utilizing a Acoustic Doppler Current Profiler) method. Diniz et al. (2013) inferred that when confronted to the velocity-area method and the acoustic method, the open channel discharge calculation is facilitated by the maximum entropy model linked with the genetic algorithm, once it has to gauge the flow velocity in only three positions on the thalweg (the cross-section lowest point) to calculate the discharge. The maximum entropy model covers all quantities of discharges in open channels. The discharge can vary from a few liters per second to millions of liters per second. The maximum 
entropy model is a helpful tool for calculating discharges in any given open channel once it generated outcomes very close to those generated by the velocity-area method and the acoustic method.

Beygi et al. (2014) examined two municipal hydraulic networks optimization project problems with different objectives, including initial costs and improvements in the networks hydraulic performance by meeting given hydraulic constraints. The main objective was to simultaneously consider the benefits of consumers and investors who are the main beneficiaries of these infrastructures. Firstly, without any input data from the interested parties, a set of acceptable solutions was calculated by a Fast Messy Genetic Algorithm. Thereafter, the appropriate alternative project was reached using two bargain models. It was concluded that the alternative obtained for both hydraulic networks shown that for constant decision-making authorities, the use of either one or the other bargain model produce the same results. It was also concluded that investors and consumers are involved. They reach $86 \%$ of their benefits using the same decision-making authority.

Haghighi and Asl (2014) created computer software, which uses the fuzzy set theory, the Non Dominated Sorting Genetic Algorithm (NSGA-II) method and a hydraulic solver (EPANET) to consider the uncertainties of the tube resistance coefficients and nodal demands in the hydraulic assessment of water distribution networks. In the suggested strategy, it was changed the notion of dominance in standpoints of density and diversity of Pareto solutions. A new measurement system called the closeness-distance was used in the standard NSGA-II instead of the crowded-comparison operator. This new measurement system orients the Pareto results into the extreme points on the Pareto fronts, which are the objective functions' global optimum values. The model was tested in a real water distribution network. It was concluded that little uncertainties (evaluation of tube resistance coefficients and nodal demands) in the network can end in big uncertainties in the hydraulic results and markedly affect the reliability of the system operation. The use of NSGA-II renders the problem solution more systematic and computationally more effective so that, many of the fuzzy hydraulic results can be analyzed concurrently in just one unique computer simulation run.

Marchi et al. (2014) presented a method for meticulous comparison of several algorithms for optimum design of water supply systems. To demonstrate the method, Genetic algorithms (GA), Particle Swarm Optimization (PSO) and Differential Evolution (DE) techniques were applied in two case studies of frequent use water supply systems and in a real water supply system composed of 476 tubes. It is concluded that the AG can give good results if it is allowed adequate function assessments. PSO performances were good in the early stages of optimization; nevertheless, they were not improved significantly when the number of evaluations increased. The DE worked well for all analyzed hydraulic networks and was plainly the best algorithm in general. However, its parameters can cover a wide variety of possible values. Marchi et al. (2014) also concluded that the performances of the algorithms depend on the specific problem and the function assessments allowed number, a correct calibration is an essential part for an equitable comparison of evolutionary algorithms and the best parameters are function of the problem features, of the objective function and of the algorithm operators' variants. Thus, the adoption of arrangements tested in little different versions of the algorithms can lead to rather differing results.

A method to calibrate the leakage parameters of an equation for a water supply network was suggested by Maskit and Ostfeld (2014). The tested network was based on an example network from EPANET. Its tubes were divided according to their properties and for each group of resulting tubes, the leakage parameters values were calculated using a genetic algorithm (GA) connected to EPANET, which changed the values of the leakage parameters to calibrate the water supply network. The results were compared with artificially generated experimental data of the network and showed reliable correspondence for the leakage parameters values.

Waldrip et al. (2016) developed a maximum entropy method to previse average outflow and inflow rates and average pressure gradients in water supply networks. The analysis is grounded on a continuous Kullback-Leibler divergence (relative entropy) determined in the universe of the current rates, needing a dimension for each extremity and node in the network. The entropy is maximized subject to observable constraints on the average values of certain current rates and/or pressure gradients, as well as physical constraints arising from node and loop constraints and the resistance properties of each tube. The developed method can be used when not enough information is accessible to use a deterministic method or when a model is updated with field gauging. The developed method also yields the capacity to use anterior knowledge about network behavior to previse current rates. A semi analytic and numeric algorithm was developed to solve the equations' system, which comprises the implicit solution of multidimensional integrals and root finding. The method was tested in two water supply networks: one with 3 nodes and 3 tubes and the other with 1123 nodes and 1140 tubes. It was concluded that the developed method broadens the methods applicable only to deterministic networks for the analysis of water supply networks. The method could bring important economies to proprietors of water assets and advisers, as less information may be necessary to acquire a satisfactory prevising of a network condition. The use of less information clearly carries a greater risk of incorrectly modeling a water supply network, mainly if the modeller lacks enough knowledge of the network being studied.

Creaco and Pezzinga (2015) developed a hybrid multiobjective algorithm for the joint optimization of tubes and control valves to reduce leaks in hydraulic networks. Firstly, the algorithm was used to the optimal valve location problem, where it investigates the tradeoff between the number of installed control valves and the everyday leak volume. The applications demonstrated the developed algorithm is more efficient than the multiobjective genetic algorithm broadly utilized in the scientific bibliography. The chief vantage of the developed algorithm is to take into account the presence of isolation valves in the hydraulic network, which can be closed to help leak mitigation and to put an end to water pathways around the control valves, thus facilitating the valves regulation. Secondly, the algorithm accomplished tube replacements and control valve installations concurrently. In this case, it was achieved a Pareto front of tradeoff solutions between installation costs and everyday leak volume. For the selection of the ultimate solution in the front, an economic discretion grounded on the long-term economic assessment was also presented. 
The purpose of this research is to show an application of the maximum entropy model coupled to a genetic algorithm to calculate discharges of any given pipe with circular cross-section.

\section{MATERIAL AND METHODS}

It is presented a method for calculating the discharge in any given pipe with circular cross-section. The flow velocity is gauged in just two positions along the pipe radius. Since the problem has two unknowns and it is necessary two equations to determine the unknowns, it is needed to gauge the flow velocity in at least two positions to find out the unknowns. The two unknowns are the maximum velocity and the entropy parameter. The method utilizes the maximum entropy model and a genetic algorithm to find out the two unknowns (parameters) of the entropy equation.

The discharge calculation in pipes with circular cross-sections is facilitated by the maximum entropy model because, as aforementioned, the flow velocity is gauged in just two positions. The genetic algorithm is utilized to facilitate the determination of the entropy equation parameters. It would take a long time to perform it without a computational tool because it is necessary an iterative method to determine the entropy equation parameters. In addition, the genetic algorithm takes a short time to find out the two parameters of the maximum entropy equation.

Figure 1 depicts $U_{\max }$. It is not possible to depict $M$. The flow velocities are gauged from the pipe wall to the pipe center as depicted in Figure 2.

To develop the method to calculate the discharge in pipes, the following equations are used:

$$
\mathrm{U}\left(\mathrm{r}_{\mathrm{i}}\right)=\frac{\mathrm{U}_{\max }}{\mathrm{M}} \ln \left[1+\left(\mathrm{e}^{\mathrm{M}}-1\right)\left(1-\frac{\mathrm{r}_{\mathrm{i}}^{2}}{\mathrm{R}^{2}}\right)\right]
$$

where: $\mathrm{U}\left(\mathrm{r}_{\mathrm{i}}\right)=$ theoretical flow velocity at $\mathrm{r}_{\mathrm{i}_{i}} \mathrm{U}_{\max }=$ maximum flow velocity; $\mathrm{M}=$ entropy parameter; $\mathrm{e}=$ the natural logarithm base equal to $2,71828 \ldots ; r_{i}=$ position along the pipe radius where the respective flow velocity is gauged; $\mathrm{R}=$ pipe radius.

$$
\varepsilon=\sum_{\mathrm{i}=1}^{\mathrm{N}}\left[\mathrm{U}_{\mathrm{i}}-\mathrm{U}\left(\mathrm{r}_{\mathrm{i}}\right)\right]^{2}
$$

where: $\varepsilon=$ error; $\mathrm{N}=$ number of gauges; $\mathrm{U}_{\mathrm{i}}=$ gauged flow velocity number; $\mathrm{i}=$ gauged velocity index $(1,2, \ldots, \mathrm{n})$.

$\frac{\mathrm{U}_{\mathrm{m}}}{\mathrm{U}_{\max }}=\frac{\mathrm{e}^{\mathrm{M}}}{\mathrm{e}^{\mathrm{M}}-1}-\frac{1}{\mathrm{M}}$

where: $\mathrm{U}_{\mathrm{m}}=$ mean flow velocity.

$\mathrm{Q}=\mathrm{U}_{\mathrm{m}} \mathrm{A}$

where: $\mathrm{Q}=$ pipe discharge; $\mathrm{A}$ = pipe circular cross-section surface. Equations 1 and 3 are results from Chiu et al. (1993). The objective function of the genetic algorithm is given by the minimization of Equation 2. The unknowns of the problem are $\mathrm{U}_{\max }$ and $\mathrm{M}$ as aforementioned. The genetic algorithm has to search for the values of the unknowns to calculate $U\left(r_{i}\right)$ yielded by Equation 1. The theoretical flow velocity calculated by Equation 1 has to minimize the error yielded by Equation 2. After finding the unknowns, the genetic algorithm utilizes the achieved values of
$\mathrm{U}_{\max }$ and $\mathrm{M}$ to calculate $\mathrm{U}_{\mathrm{m}}$ utilizing Equation 3. After calculating $\mathrm{U}_{\mathrm{m}}$, the genetic algorithm calculates $\mathrm{Q}$ of any given pipe with circular cross-section utilizing Equation 4.

The external input data (from any given pipe with circular cross-section) are as follows: the pipe radius $\mathrm{R}$, the gauged flow velocities $U_{i}$ and their respective positions $r_{i}$ along the pipe radius in at least two positions and the number of gauges $\mathrm{N}$. The number of gauges is an input data because the flow velocity may be gauged in more than two positions, but two positions are satisfactory. The internal input data for the genetic algorithm's operators are as follows: population size, number of unknowns, substring length, total string length, number of generations to be calculated, crossover probability rate, mutation probability rate, whether to use elitism or not and the scaling constant.

The experience shows that the best results are obtained when the first flow velocity is gauged from the pipe wall to the center in a position equal to $25 \%$ of the pipe radius and the second flow velocity is gauged also from the pipe wall to the center in a position equal to $90 \%$ of the pipe radius. After testing several gauging positions for each water main, as it can be seen

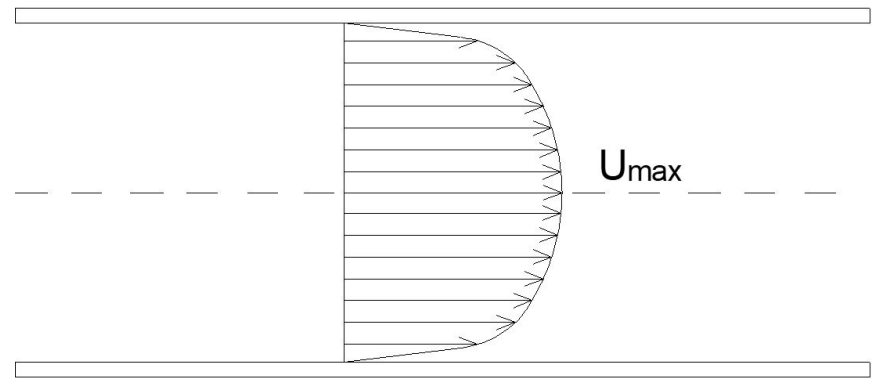

Figure 1. Velocity profile for turbulent flow of any given pipe with circular cross-section.

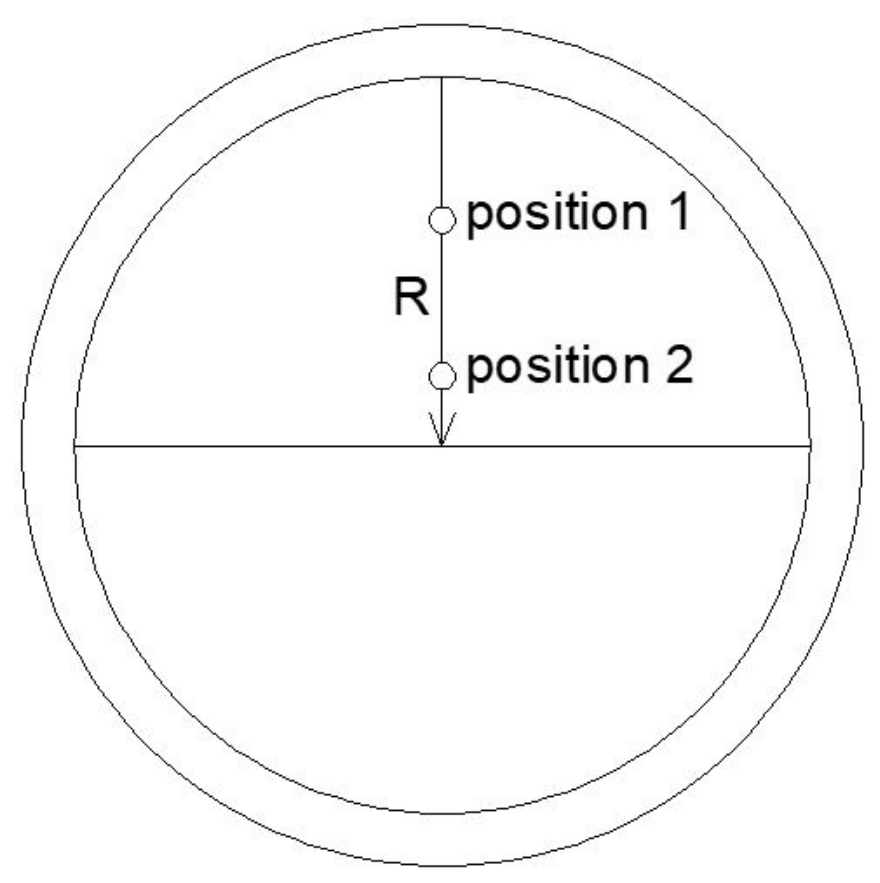

Figure 2. Circular cross-section of any given pipe. 
in Tables 1, 2, 3, 4 and 5, it is concluded that these two positions ( $25 \%$ and $90 \%$ of the pipe radius) yield the most reliable results. Besides, the maximum entropy model assumes that the maximum flow velocity is in the center of the pipe, so the flow velocities should not be measured nearby pipeline singularities because the velocity profile changes nearby such singularities and it will cause gauging errors. Due to these potential errors, gauging norms and standards are created to require flow velocities to be gauged in rectilinear pipelines for a more accurate gauging.

Table 1. Gauging positions and flow velocities by AquaProbe $\mathrm{ABB}$ for water main with nominal diameter $0.6 \mathrm{~m}$.

\begin{tabular}{cc}
\hline Gauging Position $(\mathrm{mm})$ & Flow Velocities $\left(\mathrm{m} . \mathbf{s}^{-1}\right)$ \\
\hline 20.583 & 0.324 \\
71.200 & 0.347 \\
121.700 & 0.371 \\
172.300 & 0.391 \\
222.900 & 0.401 \\
273.500 & 0.391 \\
324.100 & 0.386 \\
374.700 & 0.367 \\
425.200 & 0.340 \\
475.800 & 0.300 \\
526.400 & 0.264 \\
\hline
\end{tabular}

Table 2. Gauging positions and flow velocities by AquaProbe ABB for water main with nominal diameter $0.8 \mathrm{~m}$.

\begin{tabular}{cc}
\hline Gauging Position $(\mathrm{mm})$ & Flow Velocities $\left({\left.\mathrm{m} . \mathbf{s}^{-1}\right)}^{-1}\right.$ \\
\hline 37.166 & 0.3710 \\
104.300 & 0.4163 \\
171.500 & 0.4523 \\
238.700 & 0.4609 \\
305.800 & 0.4690 \\
373.000 & 0.4745 \\
440.200 & 0.4769 \\
507.300 & 0.4525 \\
574.500 & 0.4266 \\
641.700 & 0.3746 \\
708.800 & 0.3300 \\
\hline
\end{tabular}

Table 3. Gauging positions and flow velocities by Cole type Pitot tube for water main with nominal diameter $0.5 \mathrm{~m}$ for the first gauging trial.

\begin{tabular}{cc}
\hline Gauging Position(mm) & Flow Velocities $\left(\mathrm{m}_{\mathbf{s}} \mathbf{s}^{-1}\right)$ \\
\hline 7 & 0.67 \\
36 & 0.75 \\
75 & 0.82 \\
107 & 0.86 \\
180 & 0.91 \\
250 & 0.93 \\
320 & 0.90 \\
392 & 0.83 \\
425 & 0.80 \\
463 & 0.74 \\
492 & 0.57 \\
\hline
\end{tabular}

\section{RESULTS}

The following internal input data (parameters) are used for the genetic algorithm: a population size of 20 individuals, the number of unknowns is $2\left(\mathrm{U}_{\max }\right.$ and $\left.\mathrm{M}\right)$, the substring length is 4 , the total string length is 8 , the number of generations is 6000 , the crossover probability is 0.95 , the mutation probability is 0.02 , elitism is used and a scaling constant equal to 1.9 is used. Some other values for the genetic algorithm parameters were tested to obtain the results and it is verified the above used genetic algorithm parameters yield the best results. Besides, the genetic algorithm parameters are chosen based on literature (COLEY, 1999) and on the authors' experience. Albeit other values for the genetic algorithm parameters have been tested, it is not necessary a long time gap to figure out which values generate the best results and this has to be done only once, i.e. if one has to calculate the discharge of another pipe, the same internal input data that is used for the first can be used for the other. Discharges of three water mains were calculated and the internal input data remained the same for all three.

Theoretically, $\mathrm{M}$ ranges from zero to infinite. Chiu et al. (1993) showed Equation 1 can represent the velocity distribution in the entire flow field in a pipe, regardless if the flow is laminar or turbulent and if the pipe is smooth or rough. When $\mathrm{M}=0$, the

Table 4. Gauging positions and flow velocities by Cole type Pitot tube for water main with nominal diameter $0.5 \mathrm{~m}$ for the second gauging trial.

\begin{tabular}{cc}
\hline Gauging Position(mm) & Flow Velocities $\left(\mathbf{m}^{-\mathbf{1}}\right)$ \\
\hline 7 & 1.04 \\
36 & 1.19 \\
75 & 1.24 \\
107 & 1.31 \\
180 & 1.37 \\
250 & 1.40 \\
320 & 1.34 \\
392 & 1.27 \\
425 & 1.19 \\
463 & 1.12 \\
492 & 0.91 \\
\hline
\end{tabular}

Table 5. Gauging positions and flow velocities by Cole type Pitot tube for water main with nominal diameter $0.5 \mathrm{~m}$ for the third gauging trial.

\begin{tabular}{cc}
\hline Gauging Position(mm) & Flow Velocities $\left(\mathbf{m . s}^{-1}\right)$ \\
\hline 7 & 1.34 \\
36 & 1.56 \\
75 & 1.71 \\
107 & 1.79 \\
180 & 1.91 \\
250 & 1.95 \\
320 & 1.89 \\
392 & 1.75 \\
425 & 1.67 \\
463 & 1.52 \\
492 & 1.18 \\
\hline
\end{tabular}


flow is laminar and when $M=7$, the Reynolds number remains between $10^{5}$ and $10^{6}$, implying the flow is turbulent. For this reason and taking into account the discharges values gauged by SABESP in the three water mains, the lower and upper bound for $\mathrm{M}$ in the genetic algorithm are defined between 1 and 7. Chiu et al. (1993) also showed if the value of $\mathrm{M}$ grows up to infinite, it means $\mathrm{U}_{\mathrm{m}}=\mathrm{U}_{\max }$ and it is impossible to happen in a real flow.

To calculate the discharge of the first water main, the genetic algorithm runs 10 times and calculates 10 different discharges. The discharge chosen for the first water main is the outcome with the least error calculated by the genetic algorithm. This is done to achieve a precise outcome, once the genetic algorithm can generate a different outcome every time it runs and the aim is to show that the maximum entropy model generates reliable outcomes and can be utilized regardless other methods. It is important to remark that, albeit 10 different discharges are calculated, the discharges generated by the genetic algorithm are very close to each other each time the genetic algorithm runs. The same procedure is utilized to calculate the discharge of the two other water mains.

The flow velocity gauges obtained by the AquaProbe ABB electromagnetic flowmeter to calculate the discharge of two water mains were accomplished by SABESP (Sanitation Company of São Paulo State), Brazil. SABESP informs that the two water mains material is nodular cast iron and that the flow is fully developed for both water mains.

Table 1 shows the gauging positions and its respective flow velocities for water main with nominal diameter $0.6 \mathrm{~m}$ obtained by the AquaProbe ABB electromagnetic flowmeter from the lower water main wall to the upper water main wall.

Although the water main nominal diameter is $0.6 \mathrm{~m}$, the real water main diameter was gauged and it is $0.607 \mathrm{~m}$. To calculate the water main discharge using the maximum entropy model, the real diameter is used. The first gauging position and its respective flow velocity are $71.2 \mathrm{~mm}$ and $0.347 \mathrm{~m} . \mathrm{s}^{-1}$. The second gauging position and its respective flow velocity are $273.5 \mathrm{~mm}$ and $0.391 \mathrm{~m} . \mathrm{s}^{-1}$. These two positions and its respective flow velocities are chosen to test the maximum entropy model because they are respectively the closest positions to $25 \%$ and $90 \%$ of the water main radius. As already stated, these two gauging positions yield the best results.

Figure 3 depicts the real velocity profile in water main with nominal diameter $0.6 \mathrm{~m}$. It is obtained from the gauging data (Table 1) by AquaProbe ABB.

To calculate the error between the gauged discharge and the calculated discharge, the following equation is used for all discharges:

error $=\left|\left(\frac{\text { Device Discharge }- \text { Entropy Discharge }}{\text { Device Discharge }}\right) 100\right|$

The discharge values obtained by AquaProbe ABB electromagnetic flowmeter and by the maximum entropy model coupled to the genetic algorithm for the water main with nominal diameter $0.6 \mathrm{~m}$ are shown in Table 6 .

Table 2 shows the gauging positions and its respective flow velocities for water main with nominal diameter $0.8 \mathrm{~m}$ obtained by the AquaProbe ABB electromagnetic flowmeter from the lower water main wall to the upper water main wall.
Although the water main nominal diameter is $0.8 \mathrm{~m}$, the real water main diameter was gauged and it is $0.806 \mathrm{~m}$. To calculate the water main discharge using the maximum entropy model, the real diameter is used. The first gauging position and its respective flow velocity are $104.3 \mathrm{~mm}$ and $0.4163 \mathrm{~m} . \mathrm{s}^{-1}$. The second gauging position and its respective flow velocity are $373 \mathrm{~mm}$ and $0.4745 \mathrm{~m} . \mathrm{s}^{-1}$. These two positions and its respective flow velocities are chosen to test the maximum entropy model because they are respectively the closest positions to $25 \%$ and $90 \%$ of the water main radius.

Figure 4 depicts the real velocity profile in water main with nominal diameter $0.8 \mathrm{~m}$. It is obtained from the gauging data (Table 2) by AquaProbe ABB.

The discharge values obtained by AquaProbe ABB electromagnetic flowmeter and by the maximum entropy model coupled to the genetic algorithm for the water main with nominal diameter $0.8 \mathrm{~m}$ are shown in Table 7 .

The AquaProbe ABB manufacturer informs the device accuracy is $\pm 2 \%$. As noticed in Tables 6 and 7 , the results obtained by the maximum entropy model are very close to the results obtained by AquaProbe ABB. The errors are only $1.126 \%$ for the water main with nominal diameter $0.6 \mathrm{~m}$ and $1.540 \%$ for the water main with nominal diameter $0.8 \mathrm{~m}$. It shows the maximum entropy

Table 6. Discharges obtained by AquaProbe ABB and by the maximum entropy model for water main with nominal diameter $0.6 \mathrm{~m}$ and difference between results.

\begin{tabular}{ccc}
\hline & $\mathbf{Q}\left(\mathbf{m}^{3} \cdot \mathbf{s}^{-1}\right)$ & error $\mathbf{( \% )}$ \\
\hline AquaProbe ABB discharge & 0.10212 & 1.126 \\
Maximum entropy discharge & 0.10097 & \\
\hline
\end{tabular}

Table 7. Discharges obtained by AquaProbe ABB and by the maximum entropy model for water main with nominal diameter $0.8 \mathrm{~m}$ and difference between results.

\begin{tabular}{ccc}
\hline & $\mathbf{Q}\left(\mathbf{m}^{3} \cdot \mathbf{s}^{-1}\right)$ & error $\mathbf{( \% )}$ \\
\hline AquaProbe ABB discharge & 0.21822 & 1.540 \\
Maximum entropy discharge & 0.22158 & \\
\hline
\end{tabular}

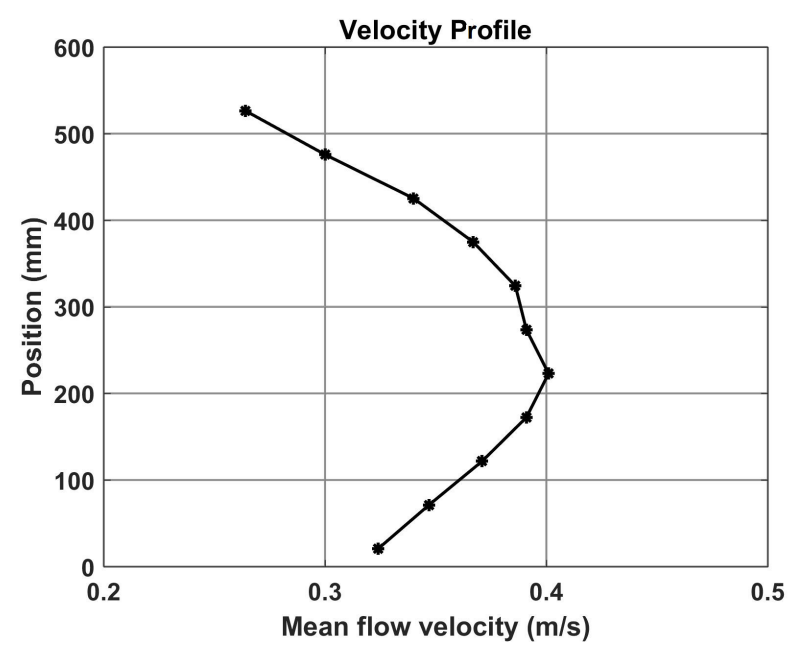

Figure 3. Velocity profile in water main with nominal diameter $0.6 \mathrm{~m}$. 
model reaches results within the accuracy of this electromagnetic flowmeter.

As it can be noticed in Tables 1 and 2, gauging the positions and flow velocities along the entire water main diameter is necessary for both water mains. SABESP report informs it takes all day long to accomplish this task for each water main. The maximum entropy model needs to gauge the positions and flow velocities along the water main radius and in only two positions.

The third water main is used by SABESP to accomplish a field gauging trial. This water main has a nominal diameter of $0.5 \mathrm{~m}$. The trial is accomplished with estimated discharges of $0.15,0.24$ and $0.32 \mathrm{~m}^{3} . \mathrm{s}^{-1}$ gauged by closing and opening a remote control valve by an operational control center. SABESP used a Cole type Pitot tube and a Venturi tube in series to respectively define the velocity profiles and gauge the discharges for this water main. SABESP informs that the third water main material is nodular cast iron and that the flow is fully developed.

Table 3 shows the gauging positions and its respective flow velocities for water main with nominal diameter $0.5 \mathrm{~m}$ obtained by the Cole type Pitot tube from the lower water main wall to the upper water main wall for the first gauging trial.

Although the water main nominal diameter is $0.5 \mathrm{~m}$, the real water main diameter was gauged and it is $0.502 \mathrm{~m}$. To calculate the water main discharge using the maximum entropy model, the real diameter is used. The first gauging position and its respective flow velocity are $75 \mathrm{~mm}$ and $0.82 \mathrm{~m} . \mathrm{s}^{-1}$. The second gauging position and its respective flow velocity are $180 \mathrm{~mm}$ and $0.91 \mathrm{~m} . \mathrm{s}^{-1}$. These two positions and its respective flow velocities are chosen to test the maximum entropy model because they are respectively the closest positions to $25 \%$ and $90 \%$ of the water main radius. As already stated, these two gauging positions yield the best results.

As noticed, the real diameters are used to calculate all discharges in the water mains. The real diameters are used because SABESP used the real diameter to gauge all discharges in the water mains, not the nominal diameters. The real diameters are used by the maximum entropy model to reach the most reliable and best possible results.

Figure 5 depicts the real velocity profile in water main with nominal diameter $0.5 \mathrm{~m}$ for the first gauging trial. It is obtained from the gauging data (Table 3 ) by the Cole type Pitot tube.

The discharge values for the first gauging trial obtained by the Venturi tube and by the maximum entropy model coupled to the genetic algorithm for the water main with nominal diameter $0.5 \mathrm{~m}$ are shown in Table 8 .

Table 4 shows the gauging positions and its respective flow velocities for water main with nominal diameter $0.5 \mathrm{~m}$ obtained by the Cole type Pitot tube from the lower water main wall to the upper water main wall for the second gauging trial.

The first gauging position and its respective flow velocity are $75 \mathrm{~mm}$ and $1.24 \mathrm{~m} . \mathrm{s}^{-1}$. The second gauging position and its respective flow velocity are $180 \mathrm{~mm}$ and $1.37 \mathrm{~m} . \mathrm{s}^{-1}$. These two positions and its respective flow velocities are chosen to test the maximum entropy model because they are respectively the closest positions to $25 \%$ and $90 \%$ of the water main radius.

Figure 6 depicts the real velocity profile in water main with nominal diameter $0.5 \mathrm{~m}$ for the second gauging trial. It is obtained from the gauging data (Table 4) by the Cole type Pitot tube.

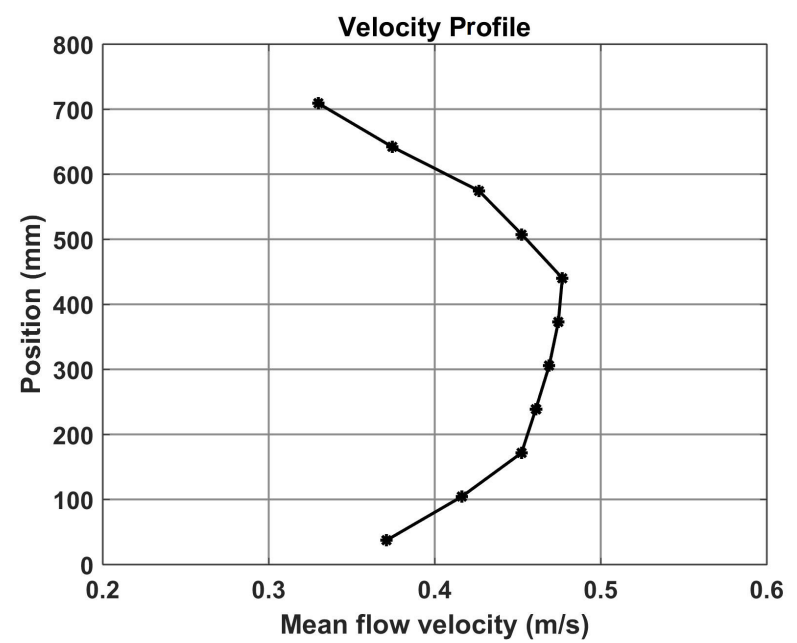

Figure 4. Velocity profile in water main with nominal diameter $0.8 \mathrm{~m}$.

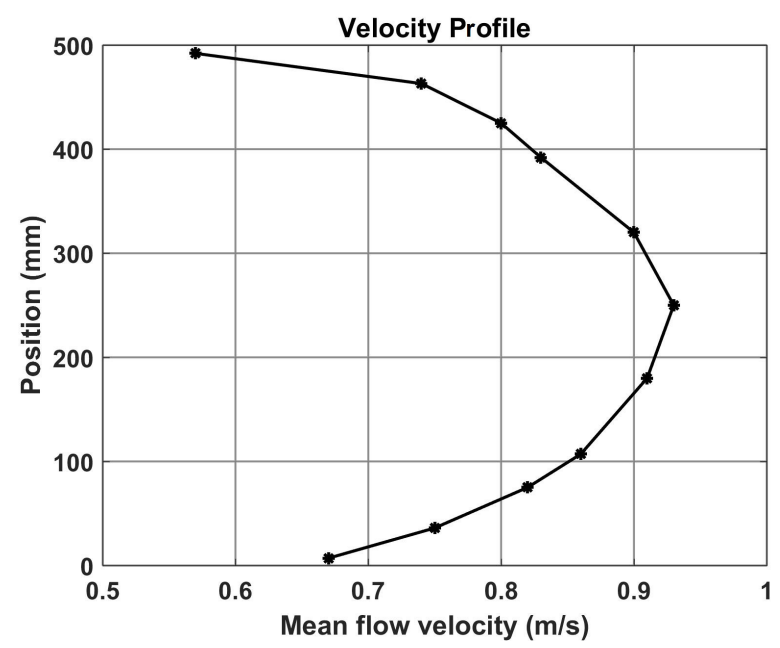

Figure 5. Velocity profile in water main with nominal diameter $0.5 \mathrm{~m}$ for the first gauging trial.

Table 8. Discharges obtained by the Venturi tube and by the maximum entropy model for water main with nominal diameter $0.5 \mathrm{~m}$ for the first gauging trial and difference between results.

\begin{tabular}{ccc}
\hline & $\mathbf{Q}\left(\mathbf{m}^{3} \cdot \mathbf{s}^{-1}\right)$ & error $\mathbf{( \% )}$ \\
\hline Venturi tube & 0.1567 & \multirow{2}{*}{0.830} \\
Maximum entropy discharge & 0.1554 & \\
\hline
\end{tabular}

The discharge values for the second gauging trial obtained by the Venturi tube and by the maximum entropy model coupled to the genetic algorithm for the water main with nominal diameter $0.5 \mathrm{~m}$ are shown in Table 9.

Table 5 shows the gauging positions and its respective flow velocities for water main with nominal diameter $0.5 \mathrm{~m}$ obtained by the Cole type Pitot tube from the lower water main wall to the upper water main wall for the third gauging trial.

The first gauging position and its respective flow velocity are $75 \mathrm{~mm}$ and $1.71 \mathrm{~m} . \mathrm{s}^{-1}$. The second gauging position and its 
respective flow velocity are $180 \mathrm{~mm}$ and $1.91 \mathrm{~m} . \mathrm{s}^{-1}$. These two positions and its respective flow velocities are chosen to test the maximum entropy model because they are respectively the closest positions to $25 \%$ and $90 \%$ of the water main radius.

Figure 7 depicts the real velocity profile in water main with nominal diameter $0.5 \mathrm{~m}$ for the third gauging trial. It is obtained from the gauging data (Table 5) by the Cole type Pitot tube.

The discharge values for the third gauging trial obtained by the Venturi tube and by the maximum entropy model coupled to the genetic algorithm for the water main with nominal diameter $0.5 \mathrm{~m}$ are shown in Table 10.

Every measurement process results in associated parameters that characterize the values dispersion to a measurand. These inherent values result from the most diverse aspects: reading errors, parallax etc. All these parameters, which characterize the gauging values dispersion, are listed and metrologically systematized. Therefore, the reference to the term "uncertainty" encompasses the expanded uncertainty that measures the inherent parameters to a given gauging. According to SABESP, the uncertainties for the first, second and third gauging trials are $3.3 \%, 3.1 \%$ and $2.8 \%$ respectively.

As noticed in Tables 8, 9 and 10 the results obtained by the maximum entropy model are very close to the results obtained by the Venturi tube in the three gauging trials. The errors are only $0.830 \%$ for the first gauging trial, $2.052 \%$ for the second gauging trial and $0 \%$ for the third gauging trial. It shows the maximum entropy model reaches results within the uncertainties informed by SABESP.

As it can be noticed in Tables 3, 4 and 5, gauging the positions and flow velocities along the entire water main diameter is necessary for the three field gauging trials. Once more, SABESP report informs it takes all day long to accomplish each gauging trial.

The maximum entropy model needs to gauge the positions and flow velocities along the water main radius and in only two positions.

Table 11 shows the maximum flow velocities, the mean flow velocities, the entropy parameters and the Reynolds numbers (Rey) obtained by the maximum entropy model coupled to the genetic algorithm for all water mains and for all field gauging trials, the maximum flow velocities, the mean flow velocities and the Reynolds numbers obtained by AquaProbe ABB electromagnetic

Table 9. Discharges obtained by the Venturi tube and by the maximum entropy model for water main with nominal diameter $0.5 \mathrm{~m}$ for the second gauging trial and difference between results.

\begin{tabular}{ccc}
\hline & $\left.\mathbf{( m}^{3} \cdot \mathbf{s}^{-1}\right)$ & error $\mathbf{( \% )}$ \\
\hline Venturi Tube & 0.2388 & \multirow{2}{*}{2.052} \\
Maximum entropy discharge & 0.2339 & \\
\hline
\end{tabular}

Table 10. Discharges obtained by the Venturi tube and by the maximum entropy model for water main with nominal diameter $0.5 \mathrm{~m}$ for the third gauging trial and difference between results.

\begin{tabular}{ccc}
\hline & $\mathbf{Q}\left(\mathbf{m}^{3} \cdot \mathbf{s}^{-1}\right)$ & error $\mathbf{( \% )}$ \\
\hline Venturi Tube & 0.3261 & 0 \\
Maximum entropy discharge & 0.3261 & \\
\hline
\end{tabular}

flowmeter for water mains with nominal diameter $0.6 \mathrm{~m}$ and $0.8 \mathrm{~m}$ and the maximum flow velocities, the mean flow velocities and the Reynolds numbers obtained respectively by Cole type Pitot tube and Venturi tube for water main with nominal diameter $0.5 \mathrm{~m}$ for the three field gauging trials.

As noticed in Table 11, the values of the maximum flow velocities, the mean flow velocities and the Reynolds numbers obtained by the maximum entropy model coupled to the genetic algorithm for all water mains and for all field gauging trials are close to the values of the maximum flow velocities, the mean flow velocities and the Reynolds numbers obtained by the devices used by SABESP. All Reynolds numbers are calculated using the real water mains diameters and a kinematic viscosity equal to $10^{-6} \mathrm{~m}^{2} \cdot \mathrm{s}^{-1}$ since SABESP hasn't yielded the water temperature.

Although the number of generations (6000) and the fact the genetic algorithm is run ten times to calculate each final discharge for all water mains, it doesn't take a long time to accomplish it.

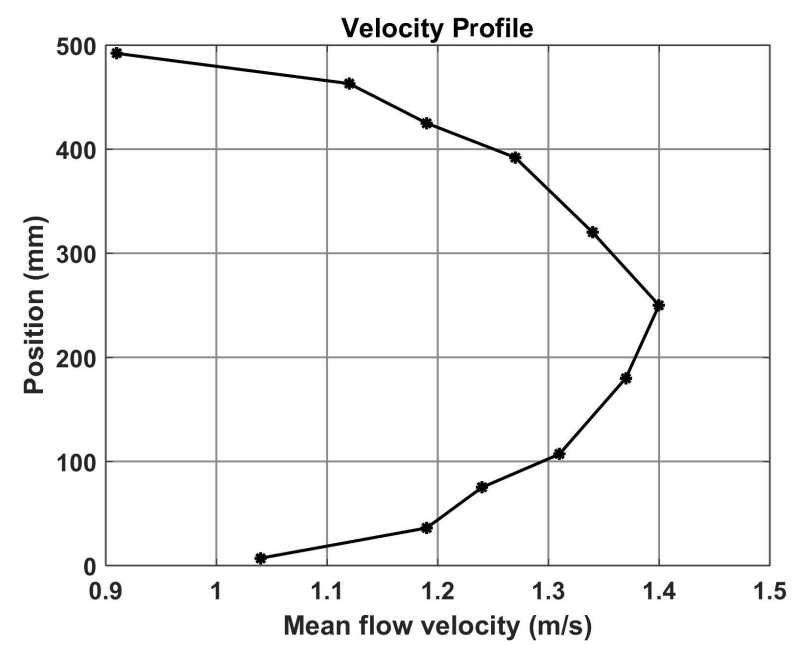

Figure 6. Velocity profile in water main with nominal diameter $0.5 \mathrm{~m}$ for the second gauging trial.

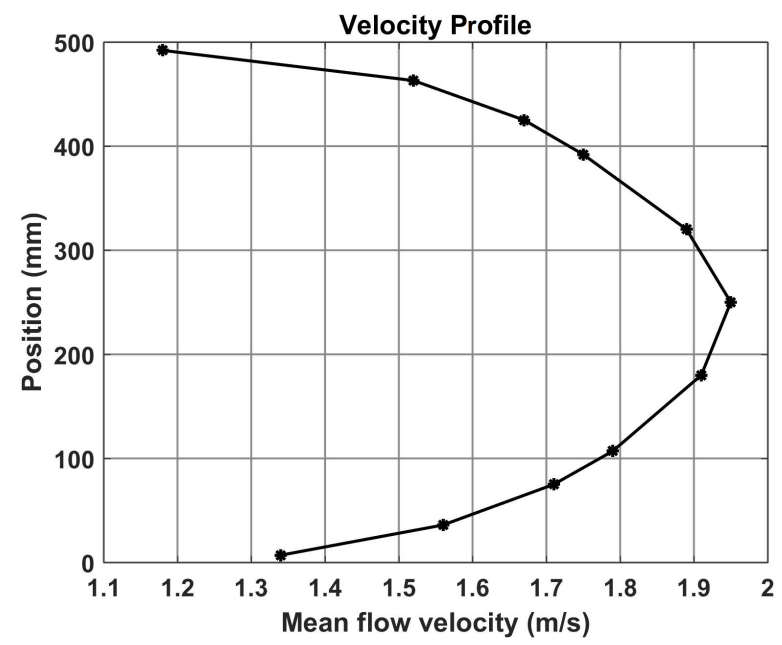

Figure 7. Velocity profile in water main with nominal diameter $0.5 \mathrm{~m}$ for the third gauging trial. 
Table 11. Maximum flow velocities, mean flow velocities, entropy parameter and Reynolds numbers for all water mains and all field gauging trials.

\begin{tabular}{|c|c|c|c|c|}
\hline & $\mathbf{U}_{\max }\left(\mathrm{m} \cdot \mathrm{s}^{-1}\right)$ & $\mathbf{U}_{\mathrm{m}}\left(\mathrm{m} \cdot \mathrm{s}^{-1}\right)$ & M & Rey \\
\hline AquaProbe ABB - water main $0.6 \mathrm{~m}$ & 0.401 & 0.353 & - & 214271 \\
\hline Maximum entropy - water main $0.6 \mathrm{~m}$ & 0.407 & 0.349 & 7 & 211843 \\
\hline AquaProbe $\mathrm{ABB}$ - water main $0.8 \mathrm{~m}$ & 0.477 & 0.428 & - & 344968 \\
\hline Maximum entropy - water main $0.8 \mathrm{~m}$ & 0.506 & 0.434 & 7 & 373984 \\
\hline Pitot tube and Venturi tube - water main $0.5 \mathrm{~m}$ (trial 1$)$ & 0.930 & 0.798 & - & 400596 \\
\hline Maximum entropy - water main $0.5 \mathrm{~m}($ trial 1$)$ & 0.922 & 0.791 & 7 & 397082 \\
\hline Pitot tube and Venturi tube - water main $0.5 \mathrm{~m}$ (trial 2) & 1.400 & 1.216 & - & 610432 \\
\hline Maximum entropy - water main $0.5 \mathrm{~m}$ (trial 2) & 1.388 & 1.191 & 7 & 597882 \\
\hline Pitot tube and Venturi tube - water main $0.5 \mathrm{~m}$ (trial 3) & 1.950 & 1.661 & - & 833822 \\
\hline Maximum entropy - water main $0.5 \mathrm{~m}$ (trial 3 ) & 1.935 & 1.661 & 7 & 833822 \\
\hline
\end{tabular}

The genetic algorithm takes less than 3 seconds to calculate each discharge. So, it means that it takes less than 30 seconds to calculate the discharges ten times. Compared to the time gap the AquaProbe ABB electromagnetic flowmeter and the Venturi tube take to calculate the discharge of any given pipe, it is quite reasonable to conclude that one would save a lot of time using the maximum entropy model coupled to a genetic algorithm, mainly because it is necessary to gauge the flow velocity in only two positions. The velocity gauges may be accomplished using an AquaProbe ABB electromagnetic flowmeter, a Cole type Pitot tube or any other device in any given water depth along the pipe radius.

\section{CONCLUSIONS}

The maximum entropy model is a useful tool to calculate discharges in any given pipe with circular cross-section because it yields results very close to the ones yielded by AquaProbe ABB Electromagnetic flowmeter and to the ones yielded by the Venturi tube. It is easier to calculate the discharge of pipes with circular cross-sections using the maximum entropy model when comparing it to the AquaProbe ABB Electromagnetic flowmeter and the Venturi tube because the maximum entropy model needs to gauge the flow velocity in only two positions along the pipe radius to calculate the discharge. The experience also shows that the best results are obtained when the flow velocities are gauged from the pipe wall to the center in a position equal to $25 \%$ and to $90 \%$ of the pipe radius, but it is necessary further investigation to understand the reason these two positions represent an efficient choice for the analyses. The upper bound value for $\mathrm{M}$ in the genetic algorithm is defined equal to 7 to prevent $\mathrm{M}$ from growing up to infinite, because it would mean $\mathrm{U}_{\mathrm{m}}=\mathrm{U}_{\max }$. The calculation of the parameters of the entropy equation is facilitated by the genetic algorithm because as aforementioned, the experience also shows it is very difficult to determine these parameters without a computational tool and because it takes only a few seconds to calculate the entropy parameters and consequently the discharge in the pipe. Consequently, the discharge calculation of pipes with circular cross-sections is accelerated by the maximum entropy model coupled to the genetic algorithm.

\section{REFERENCES}

BEYGI, S.; HADDAD, O. B.; FALLAH-MEHDIPOUR, E.; MARIÑO, M. A. Bargaining models for optimal design of water distribution networks. Journal of Water Resources Planning and Management, v. 140, n. 1, p. 92-99, 2014. http://dx.doi.org/10.1061/ (ASCE)WR.1943-5452.0000324.

CHIU, C. L. Entropy and probability concepts in hydraulics. Journal of Hydraulic Engineering, v. 113, n. 5, p. 583-599, 1987. http://dx.doi. org/10.1061/(ASCE)0733-9429(1987)113:5(583).

CHIU, C. L. Entropy and 2-D velocity distribution in open channels. Journal of Hydraulic Engineering, v. 114, n. 7, p. 738-756, 1988. http:// dx.doi.org/10.1061/(ASCE)0733-9429(1988)114:7(738).

CHIU, C. L.; LIN, G. F.; LU, J. M. Application of probability and entropy concepts in pipe-flow study. Journal of Hydraulic Engineering, v. 119, n. 6, p. 742-756, 1993. http://dx.doi.org/10.1061/ (ASCE)0733-9429(1993)119:6(742).

COLEY, D. A. An introduction to genetic algorithms for scientists and engineers. New Jersey: World Scientific Publishing, 1999. 244 p. http://dx.doi.org/10.1142/3904.

CREACO, E.; PEZZINGA, G. Multiobjective optimization of pipe replacements and control valve installations for leakage attenuation in water distribution networks. Journal of Water Resources Planning and Management, v. 141, n. 3, p. 04014059-04014059-10, 2015. http://dx.doi.org/10.1061/(ASCE)WR.1943-5452.0000458.

DINIZ, V. E. M. G.; PEREIRA, V. O. C.; BISPO, L. P.; SOUZA, P. A. Using maximum entropy for discharge calculation in open channel flow. WIT Transactions on Ecology and the Environment, v. 171, p. 301-311, 2013. http://dx.doi.org/10.2495/WRM130271.

DINIZ, V. E. M. G.; SOUZA, P. A.; LUVIZOTTTO, E. Hydraulic networks: optimizing operations through a genetic algorithm. Saarbrücken: VDM Verlag Dr. Müller, 2010. 124 p.

HAGHIGHI, A.; ASL, A. Z. Uncertainty analysis of water supply networks using the fuzzy set theory and NSGA-II. Engineering 
Applications of Artificial Intelligence, v. 32, p. 270-282, 2014. http:/ / dx.doi.org/10.1016/j.engappai.2014.02.010.

KASHIMA, A.; LEE, P. J.; NOKES, R. Numerical errors in discharge measurements using the KDP method. Journal of Hydraulic Research, v. 50, n. 1, p. 98-104, 2012. http://dx.doi.org/10.1080/ 00221686.2011 .638211

MARCHI, A.; DANDY, G.; WILKINS, A.; ROHRLACH, H. Methodology for comparing evolutionary algorithms for optimization of water distribution systems. Journal of Water Resources Planning and Management, v. 140, n. 1, p. 22-31, 2014. http://dx.doi.org/10.1061/ (ASCE)WR.1943-5452.0000321.

MASKIT, M.; OSTFELD, A. Leakage calibration of water distribution systems. In: WORLD ENVIRONMENTAL AND WATER RESOURCES CONGRESS 2014: WATER WITHOUT BORDERS, 2014, Portland. Proceedings... Reston: ASCE, 2014. p. $417-425$.

SALEH, S. H. A.; TANYIMBOH, T. T. Global maximum entropy minimum cost design of water distribution systems. In: WORLD ENVIRONMENTAL AND WATER RESOURCES CONGRESS 2011: BEARING KNOWLEDGE FOR SUSTAINABILITY, 2011, Palm Springs, USA. Proceedings... Reston: American Society of Civil Engineers, 2011. p. 206-213. http://dx.doi. org/10.1061/41173(414)22.
SHANNON, C. E. A mathematical theory of communication. The Bell System Technical Journal, v. 27, n. 3, p. 379-423, 1948. http:/ / dx.doi.org/10.1002/j.1538-7305.1948.tb01338.x.

WALDRIP, S. H.; NIVEN, R. K.; ABEL, M.; SCHLEGEL, M. Maximum entropy analysis of hydraulic pipe flow networks. Journal of Hydraulic Engineering, v. 142, n. 9, p. 04016028-04016028-23, 2016. http://dx.doi.org/10.1061/(ASCE)HY.1943-7900.0001126.

\section{Authors contributions}

Victor Emanuel Mello de Guimarães Diniz: Software writing, data processing, organization, analysis and preparation of the manuscript.

Edevar Luvizotto Júnior: Supervision, analysis and final review of the manuscript.

Podalyro Amaral de Souza: Suggested to couple the maximum entropy model with the genetic algorithm, analysis and final review of the manuscript.

Pedro Alves Silva: Former employee of SABESP, provided all field data to the manuscript, analysis and final review of the manuscript. 